\title{
Developing a dynamic framework to examine the interplay between environmental stress, stakeholder participation processes and hydrological systems
}

\author{
GEMMA CARR ${ }^{1}$, GÜNTER BLÖSCHL ${ }^{1}$ \& DANIEL P. LOUCKS ${ }^{2}$ \\ 1 Centre for Water Resource Systems, Vienna University of Technology, Austria \\ carr@,waterresources.at \\ 2 Department of Civil and Environmental Engineering, Cornell University, Ithaca NY, USA
}

\begin{abstract}
Stakeholder participation is increasingly discussed as essential for sustainable water resource management. Yet detailed understanding of the factors driving its use, the processes by which it is employed, and the outcomes or achievements it can realise remains highly limited, and often contested. This understanding is essential to enable water policy to be shaped for efficient and effective water management. This research proposes and applies a dynamic framework that can explore in which circumstances environmental stress events, such as floods, droughts or pollution, drive changes in water governance towards a more participatory approach, and how this shapes the processes by which participation or stakeholder engagement takes place, and the subsequent water management outcomes that emerge. The framework is able to assess the extent to which environmental events in combination with favourable contextual factors (e.g. institutional support for participatory activities) lead to good participatory processes (e.g. well facilitated and representative) that then lead to good outcomes (e.g. improved ecological conditions). Through applying the framework to case studies from the literature it becomes clear that environmental stress events can stimulate participatory governance changes, when existing institutional conditions promote participatory approaches. The work also suggests that intermediary outcomes, which may be tangible (such as reaching an agreement) or non-tangible (such as developing shared knowledge and understanding among participants, or creating trust), may provide a crucial link between processes and resource management outcomes. If this relationship can be more strongly confirmed, the presence or absence of intermediary outcomes may even be used as a valuable proxy to predict future resource management outcomes.
\end{abstract}

Key words water resource management, stakeholder involvement, collaboration, participation

\section{INTRODUCTION}

Water resource management is central to meeting the water challenges of the 21 st century. These challenges include floods, droughts, pollution, resource distribution and restoring and maintaining ecosystems and their services. Management decision making, implementation and the subsequent impacts of decisions on water resources are shaped by the interplay of a collection of social, economic and environmental factors (Pahl-Wostl et al. 2007). To identify and implement optimal management strategies, knowledge and understanding of the characteristics and interdependencies of the entire system is essential (Bakker 2012). This is highly complex, but as a first step, research is needed that can unpack the interactions between natural and social systems to better understand the factors influencing the management of water. One aspect of this is the role of stakeholder and public participation and collaboration in water management.

Stakeholder involvement is encouraged for a number of reasons. Management decisions developed through participative processes are often viewed as more legitimate and therefore meet less resistance at the implementation stage (Bjerregaard 1998, van de Kerkhof 2006). Participation is also able to tap into the knowledge, skills and networks of wide groups of participants and could lead to more effective solutions being identified (van den Hove 2000, Newig et al. 2005). However, the impact of collaboration on water resource management is not clear cut and detailed understanding of the factors driving its use, the processes by which it is employed, and the outcomes or achievements it can realise remains highly limited, and often contested (Conglianese 1997, Koontz and Thomas 2006, Reed 2008). Better understanding of participation is essential to enable water policy to be shaped for efficient and effective water management.

Of particular interest is the dynamic interaction between the environment, governance strategies (such as a participatory approach), and the social and environmental management outcomes which emerge as a result of the strategies employed. Previous work suggests that an environmental issue, 
such as water scarcity, can have the effect of changing the water governance system to one which includes greater stakeholder involvement. For example, persistent water scarcity has been shown to lead to a shift towards decentralised water management through local water user groups (Dinar et al. 2007). Other work shows that a system managed by farmer water user groups leads to an enhanced capacity to reduce the impacts of severe droughts on crop yields (Uphoff and Wijayaratna 2000). In a different setting, researchers report how major flood events often lead to a shift from large scale, centralised flood protection measures, to local decentralised approaches for water (and nutrient) retention at the sub-catchment scale (Bracken et al. 2012, Jordan et al. 2012). The assumption that environmental crisis events (particularly flood events) lead to changes in the governance system has been discussed by several researchers. Adger et al. (2012) use the concept of social contract theory (how governments and responsibility evolves in response to environmental risks) to examine how perceptions of flood risk and individual responsibility respond differently to an actual flood event in Ireland and England. They show that communities use political processes to create change that deals with the risks. Similarly, through an analysis of four major flood events in the UK, Penning-Rowsell et al. (2006) show that crisis events increase the rate of policy change, and often the range of actors involved, by providing a catalyst for implementing existing ideas that had previously been floated in the policy arena. Based on existing work, it is therefore expected that environmental stress events will lead to changes in the governance system that may result in more participatory approaches being employed for environmental management.

This paper outlines and applies a framework (Fig. 1) that can be used to assess how the circumstances of environmental stress events, such as floods, droughts or water pollution drive changes in water governance towards one which is more participatory. In addition, the framework links participation processes to outcomes because it is essential to gain a better understanding of how governance impacts water management.

\section{DYNAMIC FRAMEWORK FOR EVALUATING PARTICIPATION}

Using a detailed literature review approach of how participation programmes and projects have been evaluated by researchers (Carr et al. 2012), a framework has been developed for this research that captures and links together five aspects of stakeholder involvement (Fig. 1). The framework is based on a model by which environmental stress events, in combination with factors of the social setting or context, lead to specific features of a stakeholder participation process (e.g. well facilitated, representative of all interest groups, inclusive of a wide collection of knowledge) that in turn result in intermediary (often non-tangible) outcomes such as innovation, the creation of trust, shared knowledge and information or increased understanding of the views of others. Evidence suggests that features of a good participation process positively correlate to the achievement of intermediary outcomes. For example, Newig and Fritsch (2009) found that innovative solutions emerged from more intensive communication, information flow, fairness and representativeness. Intermediary outcomes do not relate to a direct change in resource management at the point in time at which they are evaluated, but evidence suggests they may be essential to achieve resource management improvements (Conley and Moote 2003, Connick and Innes 2003, Genskow 2009). The combination of the process and the emerging intermediary outcomes are therefore expected to lead to resource management outcomes such as an improvement in the ecological condition of the water resource or enhanced community resilience to drought events and improved economic well-being. These outcomes are expected to alter how environmental stress events take place and manifest themselves in the future, hence the framework is dynamic.

\section{METHODS}

Using the framework as a base with which to shape the research enquiry, eight case studies were selected from the literature and were examined in detail with regards to each aspect of the framework (environmental stress event, context, process, intermediary outcomes and resource management outcomes) (Fig. 1). The focus of the case study analysis was on the positive associations 


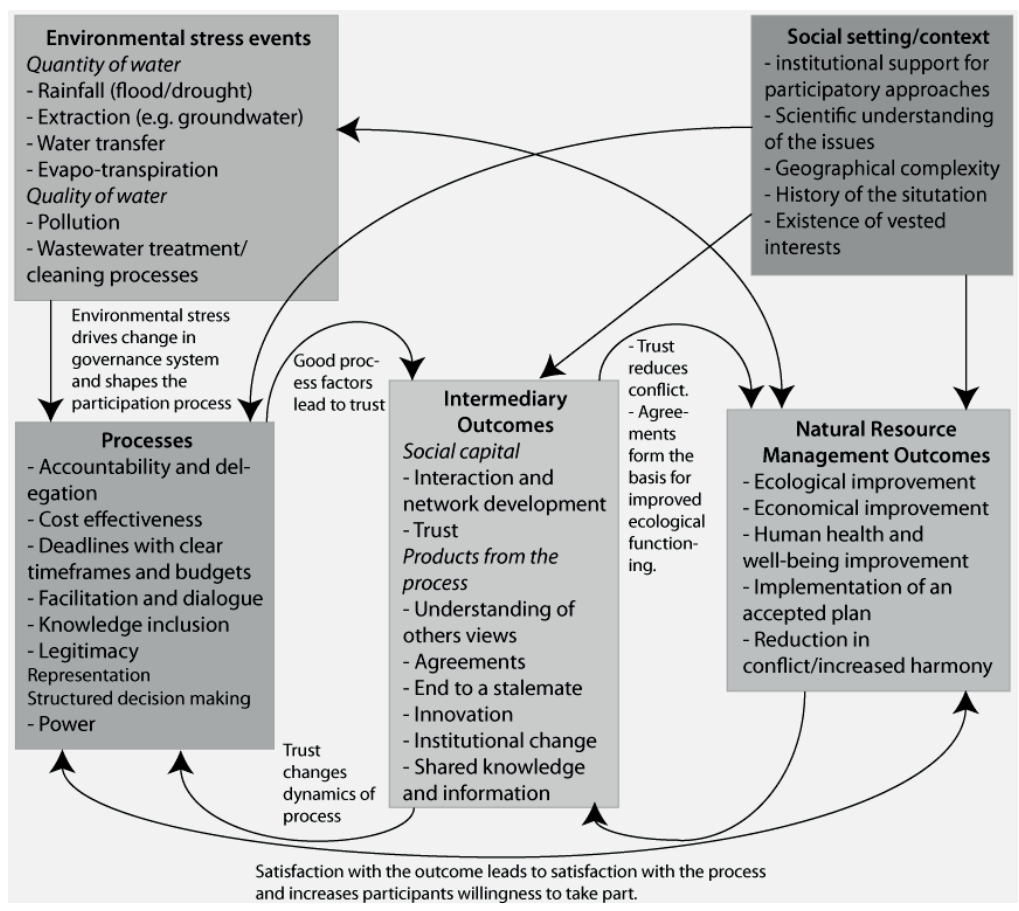

Fig. 1 Framework for evaluating the drivers of stakeholder participation, its processes and its outcomes.

between each aspect of the framework. For example, clear evidence that particular aspects of the process had led to particular intermediary outcomes.

Case studies were selected based on the quantity of information provided by the authors describing and linking the processes to the outcomes of participation. The case studies come from around the world and relate to a variety of water resource situations (Table 1). One limitation of basing the analysis on published case-studies is that it relies fully on the information on processes and outcomes provided by the author(s) of each published paper. As authors' evaluation objectives vary (some may be interested in examining how participation raises agreement between stakeholders, others in how participation leads to economic improvement) each paper may omit process and outcome associations that did not fit their objectives. Despite this limitation, the case study approach offers the potential to rapidly assess the reliability and suitably of the analysis framework to a variety of participation situations and leads to provisional findings on environmental events, processes and outcome associations.

\section{RESULTS}

The qualitative case study analysis (Table 1) reveals several important similarities between the case studies that suggest their observation is significant. Firstly, in all cases an environmental stress event (that may be due to either an existing management strategy that no longer meets the needs of the stakeholders, a greater demand for improved ecological conditions or persistent water scarcity) in combination with institutional or process manager support for participatory approaches seems to drive a participatory process to be adopted (Fig. 2). This suggests that environmental factors do stimulate a governance response, but a pre-existing interest or requirement for participation is needed to ensure that the strategy adopted includes stakeholder collaboration.

Secondly, the case study analysis is able to highlight the most common process factors, intermediary outcomes and resource management outcomes described by researchers (Table 2). This shows that seven out of the eight case studies identified facilitation as a critical process factor for achieving intermediary outcomes. Inclusion of participant knowledge and support for dialogue between stakeholders were also frequently described. The dominant intermediary outcomes identified were reaching an agreement and the construction of shared knowledge and information. Resource management outcomes tend to emerge over longer timescales and very few case studies 
Table 1 Case study analysis findings (processes, intermediary outcomes, resource management outcomes) $(\mathrm{WFD}=$ European Water Framework Directive, NA = not available).

\begin{tabular}{|c|c|c|c|c|c|}
\hline $\begin{array}{l}\text { Case study } \\
\text { and location }\end{array}$ & Reference & Environmental stress & Context & $\begin{array}{l}\text { Process factors leading to intermediary } \\
\text { outcomes }\end{array}$ & $\begin{array}{l}\text { Intermediary } \\
\text { outcomes leading to } \\
\text { resource management } \\
\text { outcomes }\end{array}$ \\
\hline
\end{tabular}

$\begin{array}{lll}\begin{array}{l}\text { Lake } \\ \text { Paijanne, } \\ \text { Finland }\end{array} & \begin{array}{l}\text { Marttunen } \\ \text { and } \\ \text { Hämäläinen } \\ \text { (2008) }\end{array} & \begin{array}{l}\text { Existing lake level } \\ \text { operating plan not } \\ \text { considered to be optimal } \\ \text { from joint ecological, } \\ \text { economic and social } \\ \text { perspective. Project } \\ \text { commissioned to } \\ \text { investigate opportunities } \\ \text { to revise the plan and } \\ \text { mitigate its adverse } \\ \text { impacts. }\end{array} \\ \begin{array}{lll}\text { Lake } \\ \text { Ontario St }\end{array} & \begin{array}{l}\text { Carr } \text { et al. } \\ \text { Lawrence }\end{array} & \begin{array}{l}\text { Existing lake level } \\ \text { operating plan based on } \\ \text { River Study, }\end{array} \\ \text { North } & & \begin{array}{l}\text { 1860-1954 hydrological } \\ \text { data set. Not performed } \\ \text { Amell under the extreme } \\ \text { high and low water supply } \\ \text { conditions experienced }\end{array} \\ \text { since that time. }\end{array}$

Tweed Collins et al. River level operating

Catchment

Plan, UK

Bargerveen Bots et al. ground and (2011)

surface water

regime,

Netherlands meeting environmental demands (sufficient wate for salmon) due to changes in agricultural water demand and diffuse pollution.

Government mandate that a ground and surface water regime should be developed for a nature conservation area
Several distinct interest groups with pre-existing mistrust of each other. Researchers selected a participatory approach specifically to gain support for the project and provide all interest groups with the opportunity to understand each other's perspectives.

Several interest groups with conflicting lake level preferences. Directive issued to investigate improved management strategy. Stakeholder participation deemed essential to define preferred strategies and reduce potential for final plan rejection by one or more interest groups. developed. An agreement was institutional change (board of control

Urban river affected by
Valley (2007) policy (dam releases)

Management

Management of water releases not satisfactory to several interest groups leading to poor relations groups leading to poor relations between groups. Researcher led
workshops specifically initiated between stakeholder groups with the aim of developing catchment management plan. (Bargerveen), home to a unique type of peat requiring high groundwater levels.

Farmers and environmentalists had different groundwater level priorities and prior negotiations had failed to reach an agreement. In line with the WFD, the national administration required the regime to be developed in cooperation with stakeholders. This was also seen as beneficial to avoid future rejection of the plan.

EU project to implement river restoration and develop a method for improved land use planning and water management in the context of the WFD (emphasis on stakeholder participation).

river restoration UK ecological condition.

Conflictive environment between water users. Research team set up

Zorrilla et al. Groundwater scarcity that Basin, Spain (2009) impacts on water availability for agriculture and wetlands.

value of Bayesian networks for developing a decision support system that could inform groundwater management.

Hase

$\begin{array}{ll}\text { Hase } & \text { Newig et al } \text {. } \\ \text { Catchment, } & \text { (2008) }\end{array}$ Germany

Diffuse nitrogen pollution Research team established an from intensive pig farming actor's platform in the catchment inhibits groundwater quality from reaching good status. to identify measures to reduce nitrogen pollution.

\section{Joint irrigation Kuper et al. Persistent water scarcity (2009) for irrigation of crops.} project,
Government subsidies available for drip irrigation but prefinancing prevents small-scale farmers taking advantage of them. Research team set up an approach to support farmer groups develop joint irrigation projects to overcome this limitation.
Well facilitated process, with dialogue supported between the participants and inclusion of participant knowledge led to increased understanding of the views of others, generated trust in the decision support tool, and more innovation in the operating plan reached by the stakeholders on the final plan.

Well facilitated process led to increased understanding of other interest groups. Inclusion of participant knowledge led to participant knowledge led to
innovation (plans improved through stakeholder input) and proposed expanded to include more interest groups).

Well facilitated process led to overcoming a stalemate between interest groups and agreement to experiment with an alternative operating policy that would better meet all stakeholder interests. New institution set up to assess how water releases could be better managed.

Well facilitated process, with dialogue supported between the participants, inclusion of participant knowledge and clear timeframe and budget constraints generated trust between the interest groups, led to shared knowledge and information and ultimately to an agreement being reached.

Broad representation of the community, well facilitated process and inclusion of participant knowledge all considered to contribute to developing an innovative restoration plan.

The agreed plan was eventually implemented after legal approval.

NA - Plan not yet agreed and implemented

\section{NA}

Funding for the agreed water regime was approved and the first stages of implementation were conducted. The development of trust, shared knowledge and information led to conflict resolution between the interest groups.

Implementation of restoration plan.

Well facilitated process, with dialogue NA supported between stakeholders and inclusion of participant knowledge led to trust developing, shared knowledge and information, and increased understanding of the views of others.

Support for dialogue between participants and inclusion of participant knowledge led to shared knowledge and information and reaching agreement on joint document of suitable measures to address the problem.

Well facilitated process, with structured and transparent decision making and delegation of

representatives to specific tasks led to shared knowledge and information on setting up a drip irrigation scheme.

\section{NA}

Shared knowledge and information accumulated through the process led to implementation of a drip irrigation scheme. 
Table 2 Frequency of process factors, intermediary outcomes and resource management outcomes described in the case studies $(n=8)$.

\begin{tabular}{|c|c|c|c|c|c|}
\hline Process factors & Total & Intermediary outcomes & Total & $\begin{array}{l}\text { Resource management } \\
\text { outcomes }\end{array}$ & Total \\
\hline Well facilitated process & 7 & Agreement reached & 4 & $\begin{array}{l}\text { Implementation of agreed } \\
\text { plan }\end{array}$ & 2 \\
\hline $\begin{array}{l}\text { Inclusion of participant } \\
\text { knowledge }\end{array}$ & 6 & $\begin{array}{l}\text { Shared knowledge and } \\
\text { information }\end{array}$ & 4 & Conflict resolution & 1 \\
\hline $\begin{array}{l}\text { Dialogue between } \\
\text { participants }\end{array}$ & 4 & $\begin{array}{l}\text { Increased understanding of the } \\
\text { views of others }\end{array}$ & 3 & & \\
\hline Broad representation & 1 & Innovation & 3 & & \\
\hline $\begin{array}{l}\text { Clear timeframe and budget } \\
\text { constraints }\end{array}$ & 1 & Trust & 3 & & \\
\hline Delegation & 1 & New institutional arrangements & 2 & & \\
\hline Structured decision making & 1 & Overcoming a stalemate & 1 & & \\
\hline
\end{tabular}

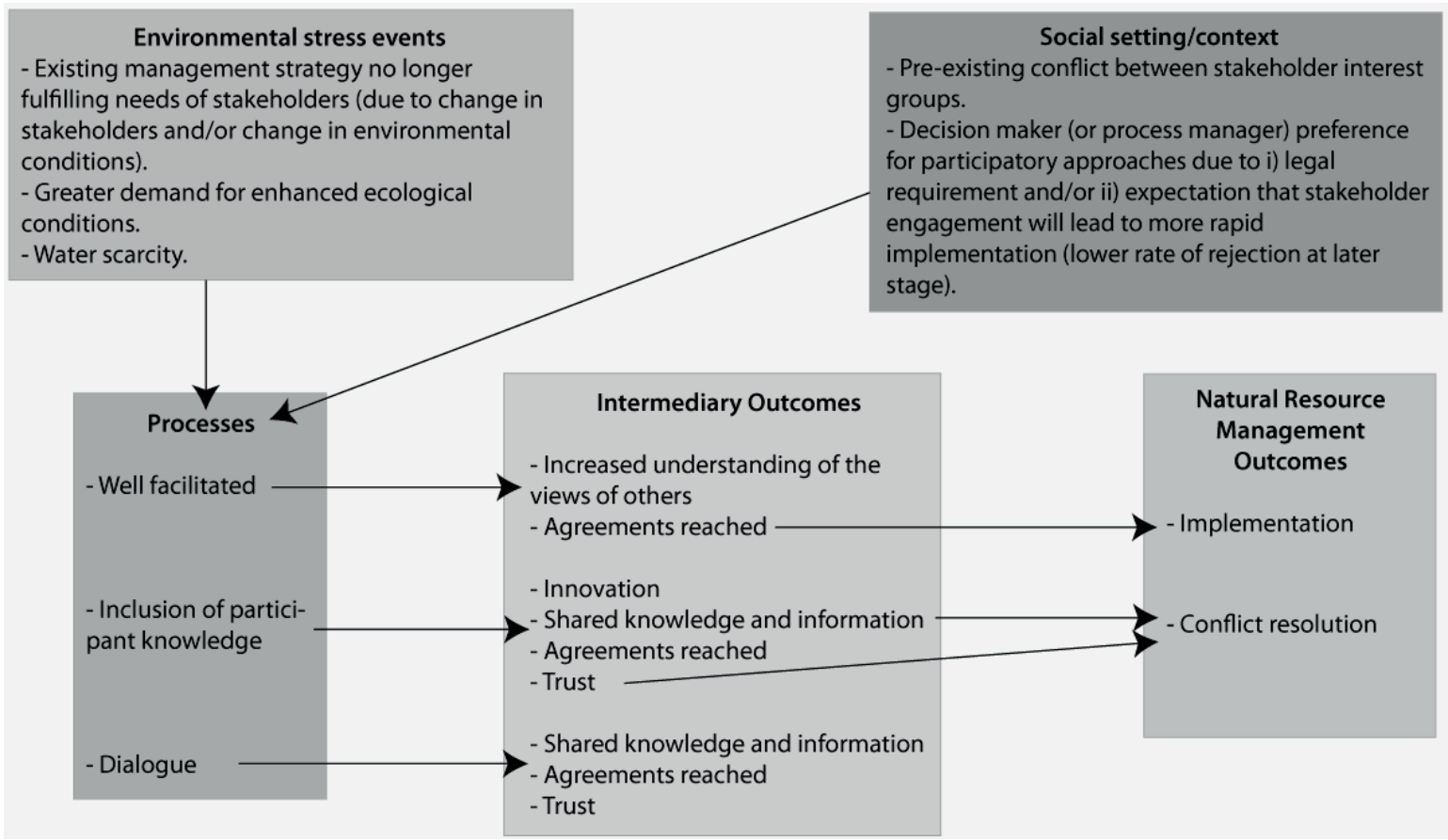

Fig. 2 Interactions between environmental stress events, context, process factors, intermediary outcomes and resource management outcomes based on Table 1. Only process and outcome relationships identified in more than two case studies are shown.

were able to identify them (Table 1), but of those that could, implementation of a plan was most frequently described (Table 2). In one case study, conflict resolution between previously feuding stakeholders was also a clear resource management outcome.

Thirdly, analysis of the most common relationships between the process factors and intermediary outcomes reveal that a well facilitated process can lead to an increased understanding of the views of others and to reaching an agreement (Fig. 2). Support for dialogue between stakeholders can lead to shared knowledge and information, reaching agreements and the development of trust. Inclusion of participant knowledge seems to lead to more innovative strategies being developed (Fig. 2). When examining the drivers of natural resource management outcomes, as expected, implementation must always be preceded by an agreement being reached. Conflict resolution seems to be dependent on trust being achieved and shared knowledge and information being developed. 


\section{DISCUSSION AND FUTURE WORK}

This research makes several important findings. The results show that participatory approaches emerge when environmental factors occur in combination with a suitable contextual situation that supports participation (i.e. there are underlying factors that promote decision makers to use a participatory approach). This finding supports that of Penning-Rowsell et al. (2006) who showed that crisis events provide a catalyst for the implementation of previously discussed, but not yet implemented ideas. The potential value of participatory approaches has been discussed for several decades and is supported by key water policy documents including the European Water Framework Directive and United States Clean Water Act. These contextual factors are likely to drive process managers to adopt a participatory approach (Table 1).

The results also show that good processes do lead to the achievement of intermediary outcomes, and that intermediary outcomes do precede resource management outcomes. This is highly relevant because intermediary outcomes can be detected earlier than resource management outcomes that tend to emerge at a later time. The work also suggests that it may be easier to identify and even measure intermediary outcomes such as the development of trust, shared knowledge and increased understanding of the views of others than resource management outcomes such as an improvement in ecological functioning, for which there is often no baseline data prior to the participation program (Ferreyra and Beard 2007).

Importantly, the results are able to show which process factors lead to which intermediary outcomes. This reveals that facilitation, inclusion of participant knowledge and dialogue are critical process factors. Many researchers have highlighted the importance of facilitation to participatory processes (see Carr et al. 2012) and this research supports the need to emphasise to those running participation programmes that a well facilitated process is critical. Inclusion of participant knowledge is less commonly identified in the literature as an important process factor but this work suggests it is also essential for achieving intermediary outcomes.

This research offers an attempt to better understand how participatory approaches emerge, and what these approaches are capable of achieving. The evaluation framework proposed has been of value in shaping the research enquiry and the provisional findings presented in this paper suggest it is both relevant and reliable. Future work is planned that will examine a greater number of case studies in order to more concretely confirm the trends identified by this research and additionally examine negative trends as it is also expected that failure to conduct participatory processes in an optimal way (i.e. poor facilitation) will lead to failure to achieve outcomes.

\section{REFERENCES}

Adger, W. N., et al. (2012) Changing social contracts in climate change adaptation. Nature Climate Change DOI: 10.1038/NCLIMATE1751.

Bakker, K. (2012) Water Security: Research Challenges and Opportunities. Science 337, 914-915.

Bjerregaard, R. (1998) Getting Europe's waters cleaner: getting the citizens involved. Water Policy 1, 73-80.

Bots, P., et al. (2011) Supporting the constructive use of existing hydrological models in participatory settings: a set of "rules of the game." Ecology and Society 16(2), 16.

Bracken, L. J., et al. (2012) Participatory approaches to understanding practices of flood management across borders. Geophysical Research Abstracts 14, EGU2012-12502, EGU General Assembly 2012.

Carr, G., Loucks, D. P. and Blöschl, G. (2013) An Analysis of Public Participation in the Lake Ontario - St. Lawrence River Study. In: Water Co-Management (ed. by V. I. Gover and G. Kratzenberg, Chapter 4. CRC Press.

Carr, G., Loucks, D. P. and Blöschl, G. (2012) Evaluating participation in water resource management: a review. Water Resources Research 48, W11401.

Coglianese, C. (1997) Assessing consensus: The promise and performance of negotiated rulemaking. Duke Law Journal 46(6), 1255-1349.

Collins, K., et al. (2007) A systemic approach to managing multiple perspectives and stakeholding in water catchments: some findings from three UK case studies. Environmental Science and Policy 10, 564-574.

Connick, S. and Innes, J. E. (2003) Outcomes of collaborative water policy making: Applying complexity thinking to evaluation. Journal of Environmental Planning and Management 46(2), 177-197.

Conley, A. and Moote, M. A. (2003) Evaluating collaborative natural resource management. Society and Natural Resources 16, 371-386.

Dinar, A., et al. (2007) Whitewater: Decentralization of river basin water resource management. Journal of Policy Modeling 29, $851-867$. 
Ferreyra, C. and Beard, P. (2007) Participatory evaluation of collaborative and integrated water management: Insights from the field. Journal of Environmental Planning and Management 50(2), 271-296.

Genskow, K. D. (2009) Catalyzing collaboration: Wisconsin's agency-initiated basin partnerships. Environmental Management $43,411-424$.

Jordan, P., et al. (2012) Catchment science and policy for agriculture and water quality. Environmental Science and Policy 24, $1-3$.

Koontz, T. M. and Thomas, C. W. (2006) What do we know and need to know about the environmental outcomes of collaborative management. Public Administration Review 66(S1), 111-121.

Kuper, M., et al. (2009) Supporting the shift from state water to community water: Lessons from a social learning approach to designing joint irrigation projects in Morocco. Ecology and Society 14(1), 19.

Marttunen, M. and Hämäläinen, R. P. (2008) The decision analysis interview approach in the collaborative management of a large regulated water course. Environmental Management 42, 1026-1042.

Newig, J. and Fritsch, O. (2009) More Input - Better Output: Does citizen involvement improve environmental governance? in In Search of Legitimacy. Policy Making in Europe and the Challenge of Complexity, ed. by I. Blühdorn, 205-224, Opladen: Farmington Hills.

Newig, J., et al. (2008) The role of formalisation, participation and context in the success of public involvement mechanisms in resource management. Systematic Practice and Action Research, 21, 423-441.

Newig, J., Pahl-Wostl, C. and Sigel, K. (2005) The role of public participation in managing uncertainty in the implementation of the Water Framework Directive. European Environment 15, 333-343.

Pahl-Wostl, C., et al. (2007) Managing change toward adaptive water management through social learning. Ecology and Society 12(2), 30 .

Penning-Rowsell, E., Johnson, C. and Tunstall, S. (2006) 'Signals' from pre-crisis discourse: Lessons from UK flooding for global environmental policy change? Global Environmental Change 16, 323-339.

Petts, J. (2006) Managing public engagement to optimize learning: Reflections from urban river restoration. Human Ecology Review 13(2), 172-181.

Reed, M. S. (2008) Stakeholder participation for environmental management: a literature review. Biological Conservation 141 , $2417-2431$.

Uphoff, N. and Wijayaratna, C. M. (2000) Demonstrated benefits from social capital: the productivity of farmer organisations in Gal Oya, Sri Lanka. World Development 28, 1875-1890.

van de Kerkhof, M. (2006) Making a difference: On the constraints of consensus building and the relevance of deliberation in stakeholder dialogues. Policy Science 39, 279-299.

van den Hove, S. (2000) Participatory approaches to environmental policy-making: the European Commission Climate Policy Process as a case study. Ecological Economics 33, 457-472.

Zorrilla, P., et al. (2009) Evaluation of Bayesian networks as a tool for participatory water resources management: application to the Upper Guadiana basin in Spain. Ecology and Society 15(3), 12. 